\title{
Porquê integrar as Universidades ao debate contemporâneo sobre o Direito Cooperativo no Brasil
}

\author{
Guilherme Krueger \\ Consultor Jurídico da Organização das Cooperativas Brasileiras \\ Comissário Especial para Direito Cooperativo da Ordem dos Advogados do Brasil - \\ Seccional do Rio de Janeiro
}

Recibido: 04.04 .08

Aceptado: 09.06 .08

O ato cooperativo, um conceito que foi proposto por Salinas Puente em 1954, encontrou no ambiente da Universidade de São Paulo, nas décadas de 60 e 70, a partir das contribuições de Waldírio Bulgarelli e Walmor Franke², vigoroso impulso para a sua positivação na legislação do Brasil.

A primeira referência de ordem legal ao ato cooperativo se deu na Instrução do Banco Nacional de Habitação n. ${ }^{\circ} 1$ de 30.11.1964³. Já no Decreto-Lei 59, de 21 de novembro de 1966, o ato cooperativo recebe tratamento tributário diferenciado, uma vez contemplado implicitamente o entendimento pela ausência nele do ânimo lucrativo ${ }^{4}$, o que já se insi-

${ }^{1}$ Natureza jurídica da Sociedade Cooperativa. 2. ${ }^{a}$ ed. São Paulo: Clássico-Científico, 1962.; Tratado Geral de Crédito Cooperativo. São Paulo: Clássico-Científico, 1964; Lições de Direito Cooperativo. São Paulo: Ceplac, 1964; Os Princípios cooperativos perante a Legislação Cooperativa. São Paulo: Ceplac, 1964; Conceito e Classificação da Sociedade Cooperativa. São Paulo: TAC, 1964; O Kibutz como entidade cooperativa. São Paulo: TAC, 1964; Regime Jurídico das Sociedades Cooperativas. São Paulo: Pioneira, 1965; O Kibutz e as Cooperativas Integrais. 3. ${ }^{a}$ ed. São Paulo: Pioneira, 1966; As Cooperativas e Plano Nacional de Habitação. São Paulo: Pioneira, 1966; Elaboração do Direito Cooperativo. São Paulo: Atlas, 1967; Regime Tributário das Cooperativas. São Paulo: Saraiva, 1974; As Sociedades Cooperativas e a sua Disciplina Jurídica. Rio de Janeiro: Renovar, 1998.

2 Direito das Sociedades Cooperativas. São Paulo: Saraiva/USP, 1973.

${ }^{3}$ Instrução BNH n. ${ }^{\circ} 1 / 64$, art. 1. ${ }^{\circ}$ : Os atos cooperativos, bem como a constituição, registro, o funcionamento e a fiscalização das cooperativas habitacionais para construção ou aquisição da casa própria serão regidos por esta Instrução. Os atos cooperativos estão regulados pelos arts. 33 a 42.

${ }^{4}$ DL 59/66, art. 18: Os resultados positivos obtidos nas operações sociais das cooperativas não poderão ser, em hipótese alguma, considerados com renda tributável, qualquer que seja a sua destinação.

Art. 23: Todos os atos das cooperativas, bem como títulos, instrumentos e contratos firmados entre as cooperativas e seus sócios, não estão sujeitos a tributação do imposto de selo ou de obrigações ou outros quaisquer que o substituam. 
nuava no Decreto 58.400, de 10 de maio de $1966^{5}$. A regulamentação do DL 59/66, através do Decreto 60.597, de 12 de abril de 1967, finalmente explicita o delineamento conceitual do ato cooperativo:

«Art. 105 - As relações econômicas entre a cooperativa e seus associados não poderão ser entendidas como operações de compra e venda, considerando-se as instalações da cooperativa como extensão do estabelecimento cooperado.»

«Art. 106 - A entrega da produção do associado a sua cooperativa significa a outorga de amplos poderes para a sua livre disposição, inclusive para gravá-la e dá-la em garantia de operações de crédito realizadas pela sociedade.»

Entretanto, o grande marco jurídico para o ato cooperativo foi mesmo a Lei 5.764/71. Não somente porque o definiú, mas porque centrou-se nele, quando normatizou pormenorizadamente o sistema operacional das cooperativas ${ }^{7}$.

Na Lei 5.764/71, o paradigma das cooperativas de produção rural está indelevelmente marcado no art. $83^{8}$, em que se descreve esse típico do ramo agropecuário de modo claramente influenciado pela co-

5 Dec. 58.400/66: Art. $23-\ldots$

Parágrafo único: Cessará de pleno direito a isenção da cooperativa que distribuir dividendos aos seus associados, não se considerando dividendos: o juro fixo até a taxa de $12 \%$ a. ${ }^{a}$, atribuído, de acordo com a legislação cooperativista vigente, ao capital social realizado, que poderá ser atualizado monetariamente nos termos do art. 261; o retorno ou sobra correspondente ao reajustamento de preços ou recebido de seus associados.

${ }^{6}$ Art. 79 da Lei 5.764/71: Denominam-se atos cooeperativos os praticados entre as cooperativas e seus associados, entre estes e aquelas e pelas cooperativas entre si, quando associados, para a consecução dos objetivos sociais.

Parágrafo único: O ato cooperativo não implica operação de mercado, nem contrato de compra e venda de produto ou mercadoria.

7 É interessante notar que o art. 83 reproduz o art. 106 do Dec. 60.597/67, que aproxima o ato cooperativo da comissão mercantil ao admitir que a cooperativa pratique atos em nome próprio perante terceiros, por conta dos interesses do sócio. O objeto dos atos são os bens que o sócio entregou à sua cooperativa.De outro lado, o art. 80 empresta ao ato cooperativo uma graciosidade inexistente na comissão. Isto é, não há no ato cooperativo uma oposição de interesses entre o sócio e cooperativa, nos moldes que tipificam a relação contratual entre o comitente e comissário. O ato cooperativo é praticado sem que a cooperativa logre obter vantagens patrimoniais para si. Neste passo assume o ato cooperativo uma eqüidistância tanto da representação civil, quanto da comissão mercantil.

8 Art. 83: A entrega da produção do associado a sua cooperativa significa a outorga a esta de plenos poderes para a sua livre disposição, inclusive para gravá-la e dá-la em garantia de operações de crédito realizadas pela sociedade, salvo se, tendo em vista os usos e costumes relativos à comercialização de determinados produtos, sendo de interesse do produtor, os estatutos dispuserem de outro modo. 
missão. Essa referência conceitual na comissão ${ }^{9}$ encontra explicação pelo fato das cooperativas agropecuárias terem efetivamente substituído casas comissárias na exportação dos produtos agrícolas brasileiros. Esse momento histórico ficou gravado no marco legal das cooperativas de 1932. O Decreto 22.239. e, seu art. 36, assim dispunha:

«Para todos os efeitos deste decreto-lei, são consideradas cooperativas centrais aquelas fundadas nas capitais dos Estados ou cidades que constituem mercados de exportação de produtos ou centros de zona economicamente dependente, com objetivo de promover a defesa integral de determinado produto ou produtos, em regra, destinados à exportação»

Essa trajetória histórica permite esclarecer a dupla perspectiva como se conceituou o ato cooperativo. Tal como a cooperativa ${ }^{10}$ e o cooperado ${ }^{11}$, que se definem de modo dúplice, também o ato cooperativo restou ambíguo: da perspectiva do mercado, a cooperativa atua como comissária, na compra e venda, agindo em seu próprio nome e portanto por conta de seus sócios. Entretanto, na operação que decorre da comissão, há dois atos (manifestações de vontade) tipicamente de mercado: o primeiro, a comissão, havido entre o comitente e o comissário e o segundo, a venda, havido entre o comissário e o terceiro comprador. Isso não ocorre na cooperativa, pois entre o sócio e a cooperativa não há oposição de interesses. Nesse passo, sob a perspectiva interna, a cooperativa atua como mandatária, pois nessa forma jurídica presume-se inexistência de oposição de interesses.

O sucesso do feito teórico pode ser aquilatado pela posterior recepção do conceito do ato cooperativo no Direito Constitucional. Pois, se é verdade que muitas Constituições se referem às cooperativas, a brasileira, de 1988, é pioneira na elevação do ato cooperativo à matéria constitucional, exigindo-se-lhe tratamento adequado, o que, longe de ser ocioso, afirma sua singularidade tal a modificar a lógica no cotejo

${ }_{9}$ «À luz do direito obrigacional vigente, procurou-se assimilar o ato da entrega ao contratado de depósito e o da comissão; agindo a cooperativa como comissária, vendendo a produção de seus associados em seu próprio nome, para posterior acerto de contas com os comitentes. Contudo, esse enquadramento não corresponde à verdadeira natureza da operação, tanto assim é que cooperativistas conscientes sentiram as dificuldades dessa assmilação, e se limitaram a afirmar, como acertadamente o fez Valdiki Moura, que as cooperativas atuam "como se fossem" comissárias, e que a entrega da produção constitui "uma espécie de consignação".» Bulgarellı. Ob. Cit, 1998. p.32

10 Associação e empresa

11 Dono e usuário 
dos fatos às hipóteses tributárias ordinariamente concebidas em face à prática de atos de mercado.

Essa trajetória dá o testemunho da valiosa contribuição universitária ao Direito Cooperativo. Mas, em que pese tal trajetória, nas décadas que se seguiram até fins do século, o ato cooperativo deixou de ser objeto de investigações acadêmicas relevantes no Brasil. Foi com Renato Becho ${ }^{12}$ que a doutrina brasileira resgata o estado das artes da teoria geral do ato cooperativo, que havia se desenvolvido no período, sobretudo na Argentina.

Esse lapso talvez em parte explique um curioso problema teórico que o Direito Cooperativo brasileiro atravessa na atualidade.

A produção intelectual oriunda da Universidade de São Paulo, de Waldirio Bulgarelli e Walmor Franke, esteve circunscrita a uma abordagem conceitual do ato cooperativo que pode ser rotulada de teoria pura, eis que os atos cooperativos o são porque bilateralmente cooperativos. Ou seja, para a prática de atos que se reconheçam cooperativos, não basta que visem o cumprimento da finalidade da cooperativa, mas também que as partes praticantes do negócio jurídico cooperem. Por esse motivo, atos de mercado e atos cooperativos são assumidos como conceitos excludentes: não há cooperação entre as partes que praticam atos de mercado.

A Lei 5.764/71 foi elaborada de modo rigorosamente fiel a essa abordagem, como deixa patente o parágrafo único de seu art. 79. Entretanto, os cooperativistas brasileiros na atualidade, quase que em sua unanimidade, preferem se referir a atos de mercado como atos cooperativos. Para reconhecê-los como tais, basta que se verifique em sua prática o cumprimento da finalidade da cooperativa, que é prestar serviços ao sócio sem a obtenção de vantagem patrimonial para si, mas em proveito exclusivo daquele sócio, na condição de usuário.

Essa abordagem do ato cooperativo, que se pode rotular de teoria mista, impõe um enorme esforço hermenêutico para a Lei 5.764/71, pois força a sua adequação a uma teoria à qual não foi originalmente pensada. ${ }^{13}$

12 Tributação das Cooperativas. São Paulo: Dialética, 1998. Três coletâneas de artigos avançaram na retomada da produção doutrinária acerca do ato cooperativo (GRUPENMACHeR, Betina Treiger [Org.]. Cooperativas e Tributação. Curitiba : Juruá, 2001; BeCHO, Renato Lopes [Org]. Problemas Atuais do Direito Cooperativo. São Paulo: Dialética, 2002; KRUEGER, Guilherme [Org]. Ato Cooperativo e seu adequado tratamento tributário. $\mathrm{BH}$ : Mandamentos, 2004).

13 Para mais detalhes a esse respeito, conferir: KRUEGER, Guilherme; DE Conto, Mario. Ato cooperativo: Considerações a partir dos pressupostos da hermenêutica filosófica. Em: KRUEGER, Guilherme (Coord). Cooperativas na ordem econômica constitucional. BH : Mandamentos, 2008. pp. 45-78. 
Não houve o que se poderia reconhecer como superação da escola uspiana. Não houve uma revisão crítica e rigorosa da produção de Bulgarelli e Franke. Poder-se-ia dizer que, em grande medida, talvez na honrosa exceção da produção de Renato Becho, essa produção anterior foi antes ignorada.

Note-se que tal afirmação não acusa um esquecimento desses autores. Ao contrário, especialmente Walmor Franke foi recorrentemente citado como referência para qualquer esforço acadêmico que se pretendesse sério em Direito Cooperativo. Mas com espantosa freqüência, esse autor foi citado em contexto de atribuir-se a ele um fundamento para o que ele jamais afirmou: que atos de mercado pudessem ser denominados como negócios cooperativos. ${ }^{14}$

Essa constatação induz ao questionamento acerca do que leva um conjunto expressivo de cooperativistas a essa subversão de linguagem, a ponto de afirmarem categoricamente compra e venda como possivelmente cooperativo, bastante que tal ato venha a cumprir a finalidade da cooperativa, quando jamais houve uma revisão teórica a superar a teoria pura proposta por Salinas Puente e desenvolvida pelos mentores intelectuais da Lei 5.764/71, ainda vigente.

Uma vez respondida essa questão, talvez se possa então especular sobre o papel da universidade na busca de novas aprendizagens acerca do Direito Cooperativo.

Quiçá Wittgenstein possa inspirar o desvendamento de um sentido na inversão de linguagem no ato cooperativo ${ }^{15}$ : na sua raiz há uma imagem agostiniana, segundo a qual o significado do ato cooperativo é aquilo que na linguagem pode substituir o seu objeto.

$\mathrm{Na}$ imagem agostiniana da linguagem, todas as palavras são nomes de algo. O que denuncia a presença dessa imagem agostiniana da linguagem no ato cooperativo pode ser a compulsão com que se buscam operações concretas para serem nomeadas de atos cooperativos. Encontrada uma operação que se nomeia como ato cooperativo, supõese então que se torna sabido o que essa expressão quer dizer.

$\mathrm{Na}$ teoria pura, há clareza que o ato praticado entre o cooperado e a cooperativa é diferente do ato de mercado. No Brasil, essa é uma questão fundamental não somente na matéria tributária, pois é de onde parte a distinção entre o trabalhador sócio da cooperativa de trabalho e o empregado, o consumidor sócio da cooperativa de consumo

14 Para mais detalhes a esse respeito, conferir o comentário 2 ao artigo 87 da Lei 5.764/71 em: Krueger, Guilherme; De MiRAnda, André Branco (Coord.). Comentários a Legislação das Sociedades Cooperativas. Vol. 1. Belo Horizonte : Mandamentos, 2007. pp. 442-443

15 SILVA, Giovane Rodrigues. Privacidade: o interior e o exterior. In: Mente, Cérebro \& Filosofia. Edição n. ${ }^{0}$ 9. São Paulo: Duetto, 2008. pp. 6-15. 
ou de eletrificação rural e o consumidor de que trata o Código de Defesa do Consumidor; entre o médico ou odontólogo sócios de cooperativa operadora e o médico ou odontólogo credenciado por empresa operadora e seus reflexos no direito concorrencial.

Por outro lado, a teoria pura não mais consegue ser bem compreendida, pois ela é basicamente uma manifestação tardia das teorias voluntaristas no Direito Civil. E as teorias voluntaristas estão cada vez menos paradigmáticas. Por isso, comumente o operador de direito e os leigos vêem o encadeamento de atos originados no interior da cooperativa e projetado para fora da cooperativa, no mercado, mas não distinguem muito bem os atos isoladamente. É um olhar que está focado na estrutura dessa cadeia. Para a problemática que se percebe com esse olhar, a teoria pura, por si mesma, não dá conta de fornecer elementos conceituais suficientes, pois ela não está preocupada em exaurir reflexão sobre a cadeia, mas apenas em identificar a sua gênese distintiva, que é a ausência de interesses opostos nos atos praticados entre a cooperativa e seu cooperado.

Por esse encadeamento, há uma tendência no operador de direito e até mesmo no leigo em unificar, chamando tudo que está encadeado, por metonímia, de ato cooperativo, para determinar um tratamento tributário, ou societário, diferenciado. Ao realizar esse processo lingüístico, a premissa distintiva fundamental entre o que acontece entre a cooperativa e seu sócio, de natureza diversa do que acontece entre a cooperativa e o mercado, resta em eclipse, mas não alterado.

É necessário reafirmar categoricamente que o ato cooperativo praticado entre a cooperativa e seu sócio não somente é praticado para o cumprimento do objeto societário e alcance da finalidade, mas os sujeitos desse ato cooperam entre si. Portanto, os interesses econômicos desses sujeitos (sócio e cooperativa) não são opostos, o que torna esse ato cooperativo essencialmente distinto de todo e qualquer ato de mercado.

A insistência com que se afirma que alguns atos de mercado são também, de certo modo, cooperativos advém da conveniência em se enfatizar a unidade e o nexo das operações econômicas da cooperativa, entendidas essas como cadeias de atos que se iniciam com um ato bilateral cooperativo, tal como reconhece a doutrina e está consagrada na redação original do art. 79 da Lei 5.764/71, mas se projetam para o ambiente externo, de mercado, para efetivação de uma vantagem patrimonial, receita ou faturamento direto para o seu sócio.

Essa insistência então se presta exatamente para designar que esses atos de mercado, quando circunscritos a uma operação da cooperativa, na qual está participante o seu sócio na dupla condição de dono e 
usuário, são praticados por conta deste. Neste passo e por dedução lógica, manifesta nessa operação a prestação pela cooperativa de serviço ao seu sócio. E inexiste, nessa operação, receita, faturamento ou vantagem patrimonial para a cooperativa.

Enfim, o esforço para o adequado tratamento permanece fundado no sentido de coerência com a ausência de interesses opostos entre a cooperativa e o seu sócio. Por isso, merece ser reconhecido que, com a prática dos atos cooperativos, a cooperativa opera no mercado em nome próprio, mas por conta do sócio.

Respondida a primeira questão, poder-se-á ver lançado o desafio de reinserção da universidade na reaprendizagem do Direito Cooperativo.

Novamente o conceito de imagem agostiniana pode ser útil para se denunciar a reprodução de uma doutrina cooperativista impregnada de senso comum: por esse modelo, a realidade se decompõe em dois mundos paralelos: o físico, manifesto em objetos, fatos, eventos e ações; e o mental, que é povoado pelas idéias associadas a esses objetos, fatos, eventos e ações. Por esse modelo, então a função fundamental das palavras é associar idéias e objetos e a função fundamental do conhecimento é descrever uma representação do objeto, mas também tomá-la como o próprio objeto. O realismo traveste-se de realidade.

As universidades em geral ressonam diversos métodos de pensamento que promoveram no séc. $x x$ a recomposição das idéias e da matéria num mesmo plano de existência. Portanto, as Universidades são capazes de colaborar na liberação do Direito Cooperativo de uma abordagem que não ultrapassa a contingência dos fatos vividos pelas cooperativas e resta desfocada do valor da cooperação que se manifesta no vivido da cooperativa.

No aprisionamento do Direito Cooperativo, a cooperação corre risco de ser mais justificativa, explicação; não tanto constitucional, fundamental ${ }^{16}$, o «vir-a-ser» dos negócios das cooperativas. Isso tem levado os cooperativistas, quando confrontados com situações não paradigmáticas, a terem seu discernimento obliterado por uma certa

${ }^{16}$ Muitos podem ser os sentidos atribuídos para constituição ou fundamento, mas o sentido aqui é aquilo que unifica ou confere validade às atividades cooperativas, como tais, cujo conjunto se organiza e se estrutura em um sistema. A crítica que se faz ao atual estado das artes do Direito Cooperativo, no que pertine à compreensão contemporânea de constitucionalidade no Direito, é a falta de exploração de um sentido de adequação hermenêutica, "consistente na interação e na interdependência entre a teoria da constituição e a experiência constitucional. A primeira, favorecendo a descoberta ou investigação das concretas soluções jurídico-constitucionais; a segunda fornecendo o material empírico indispensável para dar consistência à teoria constitucional.» (Mendes, Gilmar et al. Curso de Direito Constitucional. São Paulo: Saraiva, 2007. p. 12.) 
sofística ${ }^{17}$, quando o conceito de cooperação é reduzido a um mero elemento do ethos ou do pathos ${ }^{18}$.

Esses problemas afetaram particularmente as relações com o Direito Tributário, Trabalhista e Regulatório.

Nos anos 90, os cooperativistas prestigiaram obstinadamente a tese da intributalidade genérica do ato cooperativo. Tal tese, como já comentado neste artigo, padece com uma admissão de imunidade tácita ou oblíqua, que não se ajusta a um fundamento do direito tributário constitucional. Diante da fragilidade da tese, o fisco não se intimidou em revogar o disposto no art. 6. ${ }^{\circ}$ I da Lei Complementar 70/91 pela Medida Provisória 1858-6, em 1999, o que eliminava isenções tributárias sobre operações decorrentes do ato cooperativo. Enquanto as cooperativas insistiram com a tese nos tribunais, foram sistematicamente derrotadas, pois as lides tinham por objeto essas contribuições e os cooperativistas não logravam enfrentar o comando constitucional de custeio da seguridade social por toda a sociedade. Uma nova geração de estudiosos então se propôs a examinar a natureza das entradas e saídas nas operações decorrentes do ato cooperativo, distinguindo-as das receitas e despesas realizadas pelas empresas. A partir desse momento, o exame da tributalidade das operações decorrentes do ato cooperativo começa a demandar uma conclusão a posteriori do cotejo da operação decorrente do ato cooperativo e a hipótese tributária em espécie. A alteração da postura metodológica foi decisiva para a adequação da tributação das cooperativas pela jurisprudência promovida pelo Superior Tribunal de Justiça.

17 Sofística aqui tem um duplo sentido a partir da premissa de que ela sustenta um relativismo prático com o emprego da retórica. A primeira é a crítica ao Direito positivado, porque inadequado à natureza dos atos cooperativos, como desinteressante aos negócios das cooperativas. Mas o segundo sentido, pejorativo, é o contentamento com a verossimilhança no lugar da verdade, desde que útil aos negócios das cooperativas, ou pior: diabolicamente sedutor aos cooperativistas. Alguns dos advogados mais prestigiados pelos cooperativistas agiram como os sofistas que circularam na Grécia entre os séc. v e Iv a. C.. Os sofistas de então professavam a arte de justificar com argumentos o que quer que fosse desejado, em troca de dinheiro. Assim, freqüentemente alguns dirigentes cooperativistas foram como mágicos que se iludiram com o próprio truque: conduziram uma gestão imprudente das cooperativas, porque se agarraram a argumentos aparentemente convincentes, mas não sustentáveis, porque desprovidos de conteúdo teórico consistente ou coerente. No caso das cooperativas de trabalho, essa atitude correspondeu ao pior sentido dado por Platão à sofística: malversação do raciocínio demonstrativo para fins geralmente imorais.

18 A retórica orienta os argumentos a partir de três conceitos básicos: ethos, pathos e logos. O ethos se refere à atitude do emissor do argumento, que visa obter a confiança e aceitação pelo seu destinatário. O pathos se refere às qualidades, estados e reações do ego do destinatário do argumento, que visa despertar um sentimento. O logos se refere ao conteúdo do argumento, ao domínio da dialética, dedução, indução e analogia. O sofisma, no pior sentido, se revela como um abuso da retórica: simulação do ethos, manipulação do pathos ou falseamento do logos. 
As cooperativas de trabalho nos últimos dez anos foram envolvidas numa grande polêmica após a aprovação da Lei 8.949/94, que deflagrou um crescimento exponencial da atuação delas nos mercados de serviços terceirizáveis. Porém, a magistratura e o Ministério Público reagiram face às evidências de precarizações sistemáticas das relações de trabalho. $\mathrm{E}$ trataram de negar o acesso das cooperativas a esses mercados, através das ações civis públicas (class actions). Ao invés de buscarem meios eficazes de garantia da dignidade e decência do trabalho como modo de superação do impasse, os cooperativistas seguiam com um pensamento moldado segundo categorias do Direito Cooperativo e do Direito do Trabalho assumidas como um a priori lógico-normativo que os submetia a classificações rígidas baseadas em conceitos cooperativistas e trabalhistas excludentes. E assim, com um discurso de livre iniciativa cooperativa, eram incapazes de proporem meios preventivos eficazes face à condução das cooperativas de trabalho como instrumentos de precarização do trabalho não eventual e organizado hierarquicamente.

Também na década passada, foi colocada em cheque a unicidade da conformação sistêmica do cooperativismo, tal como imposta pela Lei 5.764/71. Vergílio Perius ${ }^{19}$ nos esclarece o caráter peculiar que a Organização das Cooperativas Brasileiras assumiu com a vigência da Lei 5.764/71: uma entidade associativa privada que, como competência delegada, realiza a guarda da doutrina cooperativista e orienta o monitoramento das iniciativas que se autointitulam cooperativas. É o que pode se chamar de entidade revisora. Trata-se de uma sistemática de autorregulação para o ambiente cooperativista, cuja recepção constitucional pode ser aferida pela ponderação dos arts. 5. ${ }^{\circ}$, XVIII e 174 da Constituição Federal. Porém, muitos dos adeptos do conceito de economia solidária renegam a unidade categórica do sistema cooperativista, atitude que é conseqüência do corte classista com que se pretende determinar a experiência do cooperativismo 20 . Sem dúvida, como fenômeno na ordem econômica, a cooperativa que se organiza como instrumento de inclusão social demanda especificidades. Mas a cooperativa de eletrificação, que pressupõe um monopólio natural, quando estabelecido o seu polígono envolvente, é evidência de que a cooperação não é essencialmente classista. Portanto, o que se evidencia é que não existe uma cooperativa essencialmente diferente na agricultura familiar e no agronegócio.

${ }^{19}$ Atenuação ou eliminação estatal tendo em vista o projeto de autocontrole. Em: De Rose, Marco Túlio (coord.). A interferência estatal nas cooperativas. Poá : Sergio Antônio Fabris, 1988. pp. 48-50

20 ReCH, Daniel. Cooperativas. Uma Alternativa de Organização Popular. Rio de Janeiro: FASE, 1995.. p. 24. 
Tanto no pensamento que restringe arbitrariamente as possibilidades de concreção da cooperação na ordem econômica, quanto no jogo sofístico que dificulta o discernimento do ato cooperativo do seu abuso, o ser e a verdade sobre o ato cooperativo se apresentam como um conjunto de presunções ou suposições com que se determina a exatidão do conhecimento acerca da concretude dos atos cooperativos.

Na raiz do inaceitável nesses jogos está a pretensão do conhecimento da cooperação no interior da experiência operacional das cooperativas. Essa aspiração cristaliza o conceito do ato cooperativo num dogma e as operações das cooperativas se fecham para uma multiplicidade dos sentidos ${ }^{21}$.

As universidades têm portanto um papel fundamental em desvendar os sentidos para cooperação no aparecer do ato cooperativo. Ocorre que há um pressuposto teórico nesse desempenho: a distinção necessária entre as operações concretas da cooperativa e a cooperação. As operações das cooperativas podem ser conhecidas por um procedimento racional de avaliação delas, pois há aí uma experiência possível, mas a cooperação só pode ser percebida e pensada22.

Mas é precisamente no valor da cooperação que o ato cooperativo vai encontrar seu fundamento último. Não é na análise dos fatos econômicos que se encontra o sentido da cooperação ${ }^{23}$. A experiência da cooperação se mostra à razão alargada como fecundação de novos sentidos para o cooperativismo na ordem econômica.

Nessa linha de reflexão acerca das Universidades, a Organização das Cooperativas Brasileiras, entidade revisora do sistema cooperativo pátrio, em 2006, elegeu, como uma ação estratégica institucional, a fertilização do pensamento cooperativista no Direito. Compõem a agenda anual da OCB o Concurso de Monografias em Direito Cooperativo, o Congresso de Direito Tributário Cooperativo e o Simpósio de Pesquisa em Direito Cooperativo.

21 O pensamento dogmático não observa os limites do conhecimento possível e positiva aquilo que não pode ser submetido a qualquer critério de cientificidade.

22 Uma contribuição intelectual muito relevante de Kant é a distinção entre o conhecimento e o pensamento estabelecida em sua Crítica da Razão Pura. Kant admite a possibilidade de se pensar conceitos a priori pelo exercício da razão, mas o conhecimento está condicionado à experiência (aquilo que é possível se apreender pelas sensações), que instaura a verificabilidade: é o tribunal crítico, em que a razão é o juiz, e os fatos são testemunhas. Portanto, não há como conhecer o amor, a liberdade, a cooperação, Deus, pois não há como submeter esses conceitos ao tribunal da razão.

23 «(....)é tão impossível atingir a essência amontoando acidentes quanto chegar à unidade acrescentando indefinidamente algarismos à direita de 0,99.» (SARTRE, J.P. ESboço para uma teoria das emoções. Porto Alegre : L\&PM, 2007. p. 17). 
Trata-se de um esforço institucional de integração das universidades brasileiras ao debate sobre o atual estado das artes do Direito Cooperativo. Embora sesquicentenário, a sociedade cooperativa é um instituto que ainda oferece muitas oportunidades para investigações inéditas e avanços significativos.

Há certamente uma difusa ambigüidade nos sentidos que se dão aos fenômenos da cooperativa, do cooperativismo e ato cooperativo. Essa ambigüidade tem a ver com a origem desses conceitos e como eles atravessaram o Séc. XX, condicionadas que foram pela evolução das idéias sociais nas sociedades ocidentais.

A origem desses conceitos se situa, é sediço, no mutualismo, uma variante de um modo de pensamento típico do Séc. xIX e que comumente é classificado como socialismo utópico. Trata-se de um conjunto de idéias, pressupostos teóricos, sentidos e propostas que não encontrou, como tal, soluções evolutivas no Séc. XX, ante a polarização entre socialismo marxista e o liberalismo e as mudanças de paradigmas de pensamento promovidas pelo estruturalismo e pela fenomenologia.

De fato, a cooperativa, uma prática que, de certo modo, cumpriu a promessa da utopia, e o cooperativismo, uma doutrina que foi cada vez mais se distanciando do socialismo que Ihe inspirou e que se moldou a partir dessa prática, sobreviveram. Mas, sem beberem na fonte das idéias sociais que lhe são originais, que restou seca, não sobrou alternativa aos cooperativistas que tomar emprestado referências de linguagem a partir de outros fluxos de pensamento.

Sem referências de linguagem singulares, os cooperativistas então lançaram mão dessa ambigüidade para lograrem demonstrar o sentido singular que intuem no fenômeno cooperativo. Assim, a doutrina cooperativista amplamente consagrada e difundida dá conta de uma dupla natureza na cooperativa ${ }^{24}$ e uma dupla qualidade no sócio ${ }^{25}$. Essa du-

${ }^{24}$ A Aliança Cooperativa Internacional recepcionou em sua definição a Dupla Natureza da cooperativa expressa na sua dimensão associativa e empresarial. O cotejo desta posição com a adotada pelo Novo Código Civil brasileiro revela toda a tensão conceitual. Define o Código Civil a cooperativa como sociedade simples, em contraste exatamente com as associações e as empresas. Portanto, para os pensadores do Direito pátrio, poder-se-á sintetizar essa dupla natureza pelos seguintes sentidos: uma natureza social, porque pressupõe a participação solidária dos cooperados na condição simultânea como donos e usuários do empreendimento - portanto, interagem no ambiente social através da Cooperativa; e uma natureza societária, porque a missão de uma cooperativa é sempre o desenvolvimento econômico de seus sócios.

${ }^{25}$ Dupla Qualidade do sócio é a denominação que se dá ao pressuposto de que a cooperativa, como sociedade, é gerida pelo sócio em regime de autogestão, e este é o meio de consecução dos objetivos da cooperativa, ou seja, a prestação de serviços que satisfaçam os interesses econômicos comuns dos próprios sócios, assim, destinatário dos 
plicidade denuncia à consciência a ambigüidade com que a cooperativa se manifesta para as intencionalidades doadoras de sentidos singulares ao fenômeno da cooperativa.

Isso traz problemas de segurança e certeza, mas também fertiliza o pensamento, enriquece os debates sobre o estado das artes e sobretudo potencializa o universo de possibilidades de sentidos que podem ser descobertos.

A começar pela perspectiva da própria idéia social que lhe deu vida, no confronto com a realidade jurídica contemporânea, o cooperativismo hoje manifesta no Direito algo já intuído por John Rawls em sua crítica ao utilitarismo ${ }^{26}$ : as pessoas possuem diferentes valores e formulam diferentes projetos para a realização do bem comum. Às vezes, esses projetos versam sobre o mesmo objeto e realidade e, mesmo assim, são heteronômicos.

Neste passo, a cooperativa é um fenômeno que, mais do que colocar a nu o já ultrapassado dogma hermenêutico da unidade monolítica do Direito, traz elementos para uma reflexão crítica para determinadas noções de Justiça contemporâneas e se abre como um universo particularmente rico para aplicação de pressupostos hermenêuticos com foco nos valores constitucionais.

resultados das atividades societárias, como seu usuário. O sócio é titular da sociedade e usuário dos serviços da sociedade (satisfaz suas necessidades e aspirações econômicas). Daí porque os resultados são distribuídos conforme as operações, e não conforme o capital de que é proprietário.

${ }^{26}$ «A proposição central do utilitarismo, pelo menos na sua forma clássica, é o princípio da maior felicidade. De acordo com este princípio, o melhor resultado é aquele que maximiza a felicidade agregada dos membros de uma sociedade tomada como um todo. Todavia, em algumas circunstâncias plausíveis, pode acontecer que a maneira de maximizar a felicidade agregada signifique impor um sofrimento considerável a um ou a alguns membros de uma sociedade.

«(....) Na opinião de Rawls, ainda que os utilitaristas aceitem que diferentes coisas contribuam para o bem, pressupõem que isso acontece porque contribuem para o bemestar psicológico, que é, só por si, o único bem. Rawls pensa que este pressuposto está errado. Na sua perspectiva, há uma concepção pluralista de diferentes e até incomensuráveis concepções de bem e assim continuaria a ser mesmo que todas as pessoas fossem muitíssimo informadas e racionais. As pessoas possuem diferentes valores e formulam diferentes projetos. Alguns destes valores e projetos ultrapassam a sua própria vida e experiência individual. Isso é, alguns indivíduos — muitos indivíduos, de fato- valorizam outras coisas para além de estados mentais ou estados de bem-estar psicológico.» Johnston, David. The Idea of a Liberal Theory: A Critique and Reconstruction. New Jersey: Princeton Universtity Press, 1996, pp. 101-3 (Trad. Vítor João Oliveira). 